\title{
Design and Implementation of an Intelligent Online English Learning System Based on Mobile Internet Technology
}

\author{
https://doi.org/10.3991/ijet.v16i24.27835 \\ Ying Liu ${ }^{1}$, Hong $\operatorname{Yan}^{2}(\bowtie)$ \\ ${ }^{1}$ Chengde Medical University, Chengde, China \\ ${ }^{2}$ Beijing Jiaotong University Haibin College, Huanghua, China \\ hyaneczjtu.edu.cn
}

\begin{abstract}
A predicament facing education is that the traditional teaching mode could no longer meet the requirements of modern society. The fast development of mobile Internet technology has brought online education platforms into existence, and these newborn things are very helpful to solve the mentioned contradiction. To deepen the research of the application of mobile Internet technology in modern education, this paper designed the functional modules of an intelligent online English teaching (IOET) system and implemented the proposed system. In our study, satisfying students' learning requirements had been taken as the core principle when building the proposed system, and the database design had followed the principles of standardization, consistency, security, integrity, scalability, and ease of maintenance. The IOET system adopts a three-layer architecture, from top down, the system has a representation layer, a business logic layer, and a data service layer. The main management modules of the system include course notification module, visitor management module, and homework management module, etc. Through this paper, we hope to provide a piece of evidence for the basic research on the upgrade and improvement of intelligent online English teaching platforms.
\end{abstract}

Keywords-mobile Internet, education mode, online education platform, English learning, system architecture

\section{Introduction}

The invention of information digitalization technology and data transmission technology has greatly accelerated the development of online learning, with the aid of these technologies, major online learning platforms are able to update their online courses constantly, rapidly, and massively [1]. The emerging online learning systems have well solved the problem of educational resource imbalance, and the Internet technology has contributed a lot to educational resource sharing [2, 3]. Using wireless mobile communication technology and equipment, online learners can access to educational resources undifferentiatedly and carry out digital learning without the limitation of time and space $[4,5]$. Learners can choose platforms, teachers, and teaching contents freely at their 
will, and the application of artificial intelligence and big data has enabled the platforms to master users' learning situations more accurately so that they could provide targeted teaching service and realize personalized education [6].

The popularization of intelligent media such as the various mobile devices has provided good learning conditions for learners, they can use these devices to learn and communicate with teachers or other learners anytime anywhere based on their personal needs $[7,8]$. Now, online learning is developing towards the direction of miniaturized, intelligent, and ubiquitous [9 10]. A main technology of the Internet-based intelligent online learning is the data mining technology, which can be used for any data type [11, 12]. In China, under the joint promotion of online education institutions and enterprises, course-teaching and tutorial-class style online learning platforms have become the mainstream form of online learning [13]. A variety of online learning platforms have sprung up one after another, such as MOOC, chuanke.com, and the mobile app of "Xuexitong" developed by Chaoxing, etc., and the corporation between online learning platforms, education institutions, and teachers has become a new mode of online education in China [14]. Such new mode has reformed the traditional education mode, broken temporal and spatial restraints, and enabled students to use their time fragments to learn at any time they want [15].

Then, with the fusion of information technology and video communication technology, the form of online education has been greatly diversified, and the user group is growing continuously $[16,17]$. Taking online English learning system for example, since students of different grades and groups need to learn different knowledge, different knowledge databases need to be built on a same platform [18]. The popularization of mobile apps is bound to create fierce competition, and the design and development of an online app requires technical support such as cloud service, platform construction, course preparation, and system docking, etc. $[19,20]$. Based on the mobile Internet technology, this paper designed the functional modules of an IOET system and implemented the proposed system.

\section{Requirement analysis of the IOET system}

Online learning systems are the products of the development of the times, they are useful auxiliary teaching tools with extensive functions [21]. The biggest feature of online learning is the huge user crowd [22]. Requirements for the IOET system could be divided into two parts: first, the system should be able to provide rich online service methods, since there're differences in the knowledge level, follow content, online learning method, and learning time of users, their requirements for the service provided by the system are multitudinous [23]; second, the system should be able to reduce learning cost and improve learning efficiency, and this requires to build a sound functional structure of online learning system, and realize English text analysis and knowledge library query [24]. Figure 1 shows the statistics of students' evaluation on online learning. $58.49 \%$ of them think online learning is very good or good, only less than $15 \%$ of them think it's not good or they don't like it. 


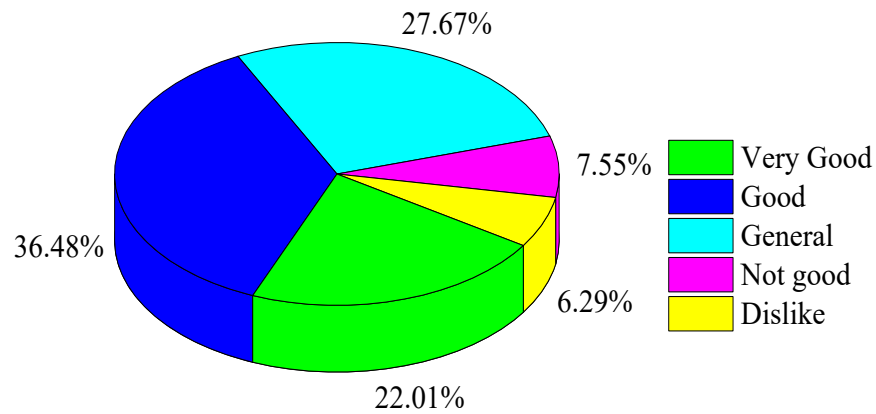

Fig. 1. Students' evaluation on online learning

At present, the online learning of higher education is mostly carried out in a dual mode: both online teaching and offline teaching are conducted at the same time, students preview relevant course chapters in advance on the mobile learning platform, then they bring questions to the offline class, they learn the basic knowledge using afterschool hours, in class hours, they learn through practice and communication under the guidance of teachers [25]. Students can use the terminal apps installed on mobile phone, laptop, or ipad to access to the IOET system, which could free them from the limit of space and realize mobile learning $[26,27]$. Now, modern education has entered a postMOOC era, and the walls of colleges and universities are being torn down; in the past, intelligent education could only serve students on campus, while in the future, it could serve all people for their lifelong education [28, 29]. In the coming future, online learning systems will become more convenient, and the interactive learning environment will get better [30]. Pedagogical researchers have pointed out that, we need to create a test platform with easy access, friendly interface, and complete functions for students so that they could operate the online learning platform better and faster, and their learning initiative could be activated; in addition, we also need to establish a new lecturing and learning mode for teachers and students, explore the possibility of enhancing collaborative learning between students, and create the opportunity to realize students' requirements for the IOET system $[31,32]$.

\section{Overall design of the IOET system}

\subsection{Design principles and goals}

Goals of the IOET system include: optimizing the process of school teaching management activities, getting real-time feedback data of teaching and learning situations, and generating dynamic and complete teaching and learning databases. Fragmenting the English knowledge points is conductive for students to use their time fragments to receive the knowledge, which is beneficial to improving their learning effect, they can review the key and hard knowledge points repeatedly. Figure 2 lists the design principles of the IOET system. The first one is accurate system positioning, which means that 
the mobile online learning environment should be created with students' learning requirements as the core; the second principle is flexible learning mode, students are the subjects of online English learning, the system should provide personalized learning modes for them flexibly, such as the seminar-style learning mode, etc. The third principle is friendly interface and simple operation, interface design should be concise and eye-pleasing, the prompt information should be pushed using text messages to reduce the impact on mobile learning as much as possible. The fourth principle is to save expenses and reduce learning costs. Figure 3 summarizes the features of online learning into four points: personalized self-directed learning, mobile learning environment, diverse learning resources, contextual and interactive learning process.

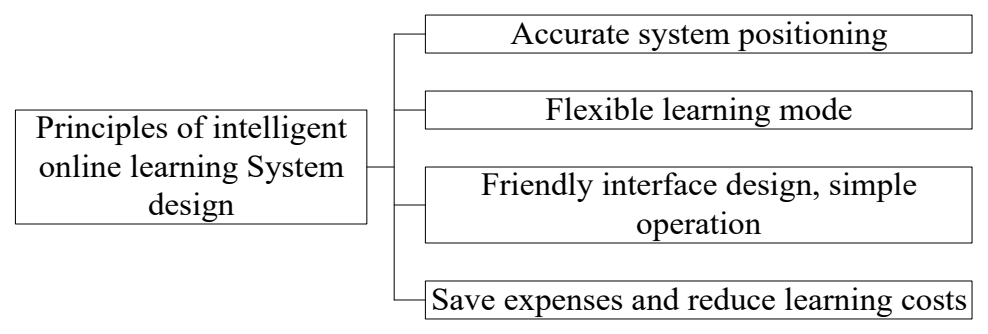

Fig. 2. Design principles of the IOET system

\begin{tabular}{|c|c|}
\hline & Personalization of self-directed learning \\
\hline & Mobility of the learning environment \\
\hline \multirow{3}{*}{$\begin{array}{c}\text { Features of } \\
\text { online learning }\end{array}$} & \\
\hline & Diversity of learning resources \\
\hline & $\begin{array}{c}\text { Contextualization and interactivity of the } \\
\text { learning process }\end{array}$ \\
\hline
\end{tabular}

Fig. 3. Features of online learning

\subsection{Database design}

The IOET system was designed and developed based on mobile platform development environment, AI, data mining, and theories about learning. It could teach learners according to their different learning habits, cognition characteristics, and knowledge levels, and it could adjust the learning progress and content in a timely manner according to the learning level and status of the students. Figure 4 shows the principles of database design, including standardization, consistency, security, integrity, scalability, and ease of maintenance. The validity, correctness, and compatibility of the data are the basis to ensure the integrity of the database. A mature system must be a complete set of operations which can make full use of the existing scientific knowledge and the thinking logic of the system. The core part of database design is data mining, which can discover different types of knowledge and analyze them from different perspectives. Figure 5 shows the database mining process, including three stages of data preparation, 
data mining, result expression and interpretation. The data preparation stage contains steps of data integration, data selection and data pre-processing.

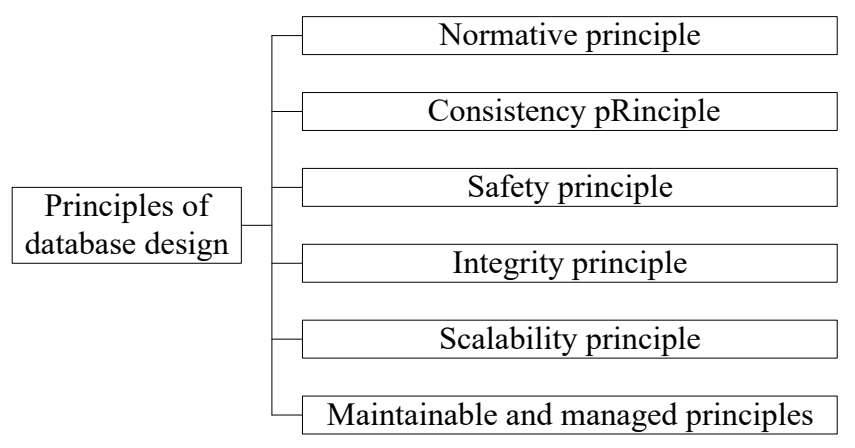

Fig. 4. Principles of database design

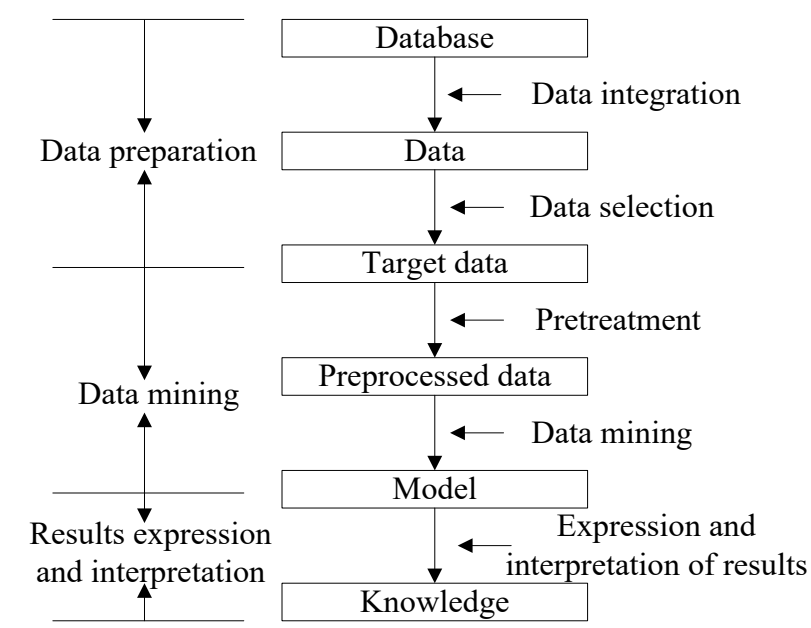

Fig. 5. Database mining process

\section{Module design and system design of the IOET system}

\subsection{Module design}

The proposed IOET system contains two parts: web-end management system, and the mobile-end app. Teachers use web browser to publish and manage teaching resources, analyze and evaluate students' learning situations; students use mobile equipment to conduct online learning. Figure 6 shows the overall functions of the IOET system. Main functions of the web-end management system include: question bank import, video upload, question bank management, test management, user management, score analysis, and test question analysis. Main functions of the mobile-end app include: login 
\& authorization, question bank exercises, online exams, teaching videos, history records, exam rankings, and personal information, etc.

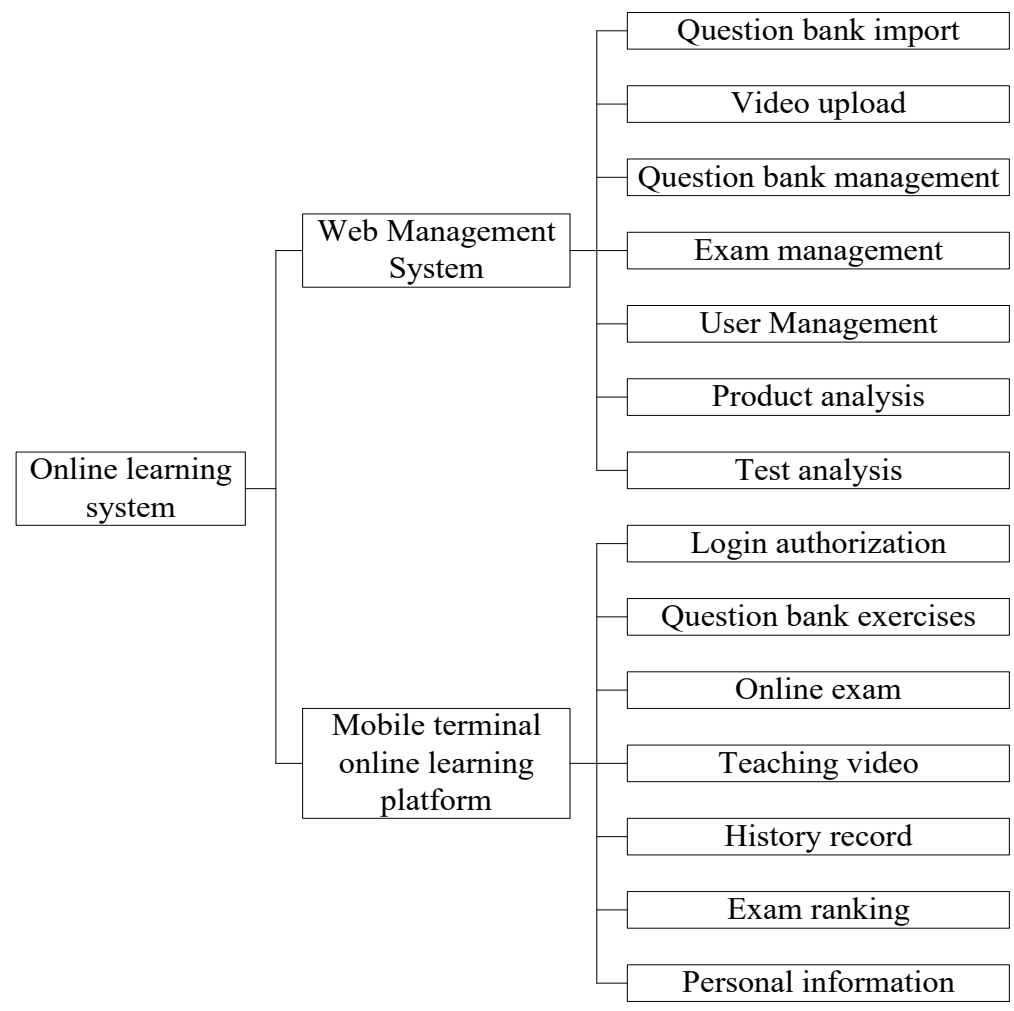

Fig. 6. Overall functions of the IOET system

Figure 7 gives the function structure of the IOET system. As can be seen from the figure, the system contains teacher module, knowledge library module, student module, and human-machine interaction module. The teacher module mainly solves problems in teaching, it updates the knowledge library in a timely manner according to the learning status and effect of students; the student module establishes student models; the human-machine interaction module supports users to interact and communicate with the system smoothly. The proposed IOET system can instruct students to use English to raise and answer questions, and it builds a channel for the communication and exchange between students and teachers. Figure 8 gives the technical framework of the IOET system. The proposed system adopts a three-layer architecture, from top down, a representation layer, a business logic layer, and a data service layer. The presentation layer receives the data input by users, then displays the data after processing. The business logic layer acts as a bridge between the presentation layer and the data service layer, it is the core of the system, mainly responsible for business logic processing and data transmission. The function of the data service layer is implemented by the server- 
end of the system, it offers services such as transmission, storage, and analysis of question bank files, and it could perform database addition, deletion, and alteration operations according to the received requests.



Fig. 7. Function structure of the IOET system

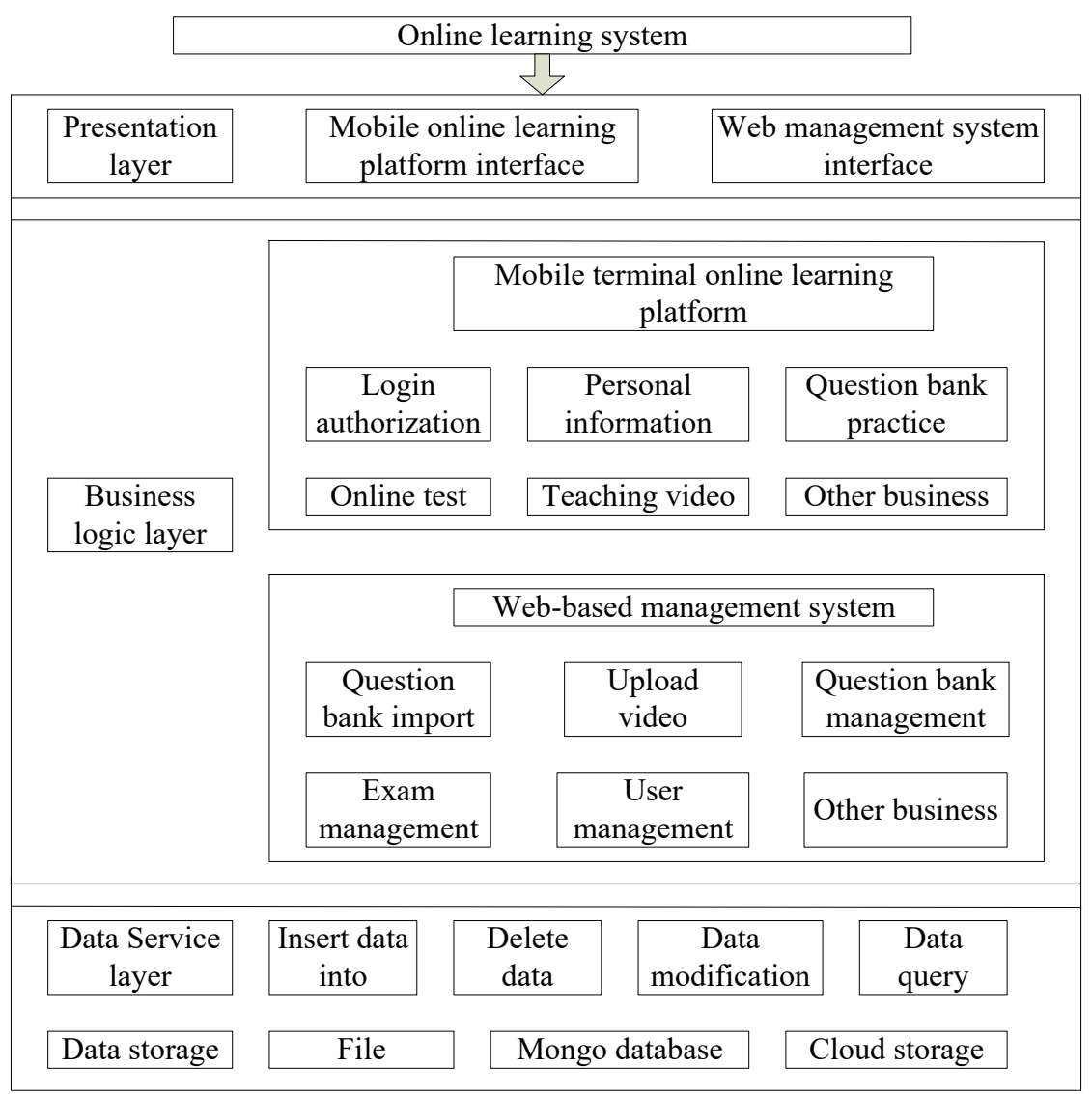

Fig. 8. Technical framework of the IOET system 


\subsection{System design}

The intelligent feature of the proposed IOET system is mainly reflected as the personalized learning methods. Figure 9 shows the architecture of the IOET system, the entire system takes students and the core of the architecture, it could give personalized teaching and analyze students' learning habits according to their learning situations, then, based on the analysis results, the system automatically chooses different learning paths for students to adapt to personalized learning with students as subjects; after that, the system judges students' characteristic information through their learning history records, and adjusts the teaching arrangement to let it fit different learners. Moreover, the system realizes account management through the addition, deletion, and modification of user information. Figure 10 is a diagram of the account management module. The module functions include: create, update, and delete system administrators; create, update, and delete teacher users; create, update, and delete student users. Figure 11 is a diagram of the English course resource management module. The module functions include: course video resource management, courseware management, and after-school exercise management; wherein the course video resource management operations include: create, update, and delete video information; the courseware management operations include: create, update, and delete courseware information; and the after-school exercise management operations include: create, update, and delete after-school exercises. Figure 12 is a diagram of the online learning management module. The module functions include: course notification management, visitor management, and student homework management; wherein the course notification management operations include: create, update, and delete course notifications. Figure 13 is an input-processoutput diagram of online learning management. The input modules contain learning information, query request, and exit request. The process modules contain permission judgement, database retrieval, database processing, and process termination. The output modules contain return with permission, return without permission, display learning information, return operation result, and prompt exit.



Fig. 9. Architecture of the IOET system 
Paper-Design and Implementation of an Intelligent Online English Learning System Based on Mobile...

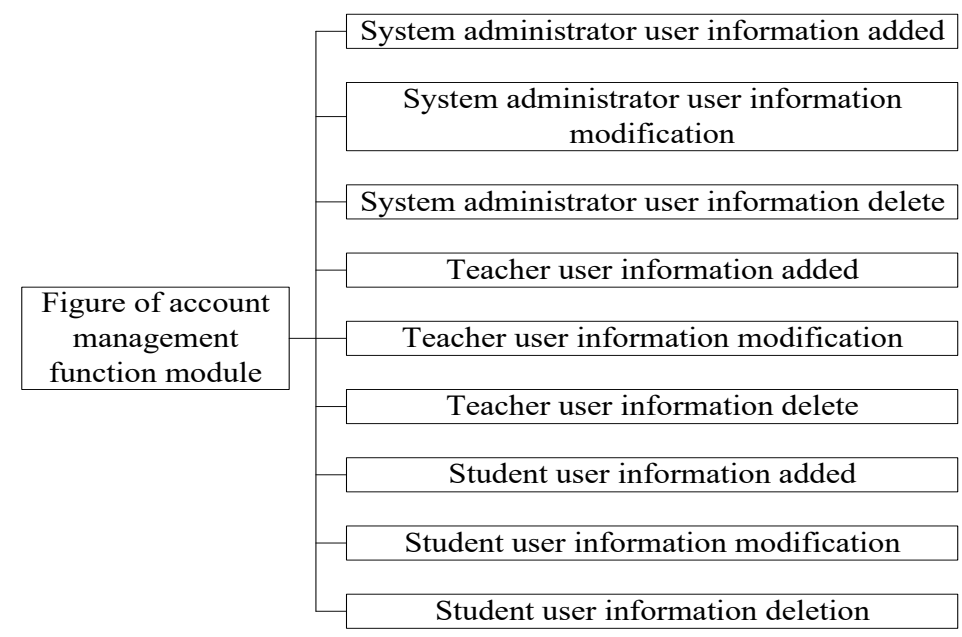

Fig. 10. The account management module

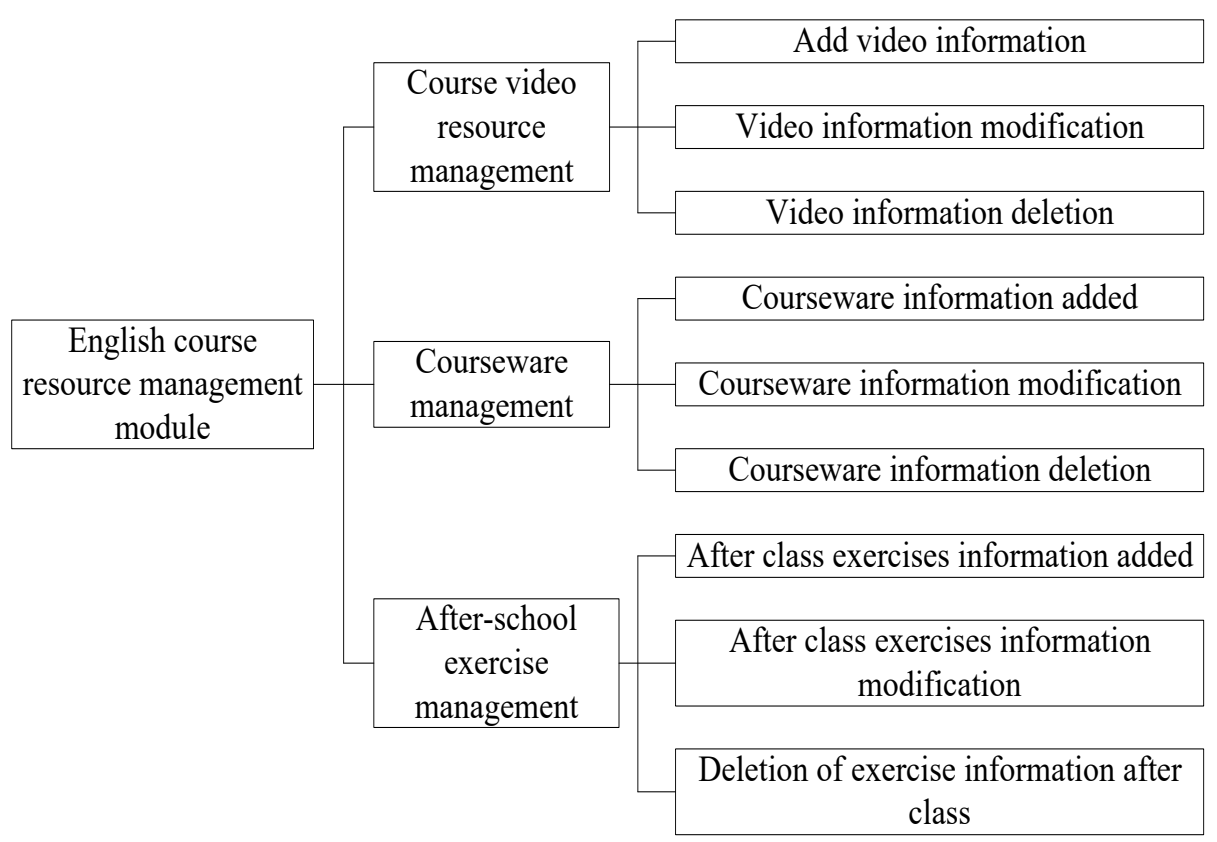

Fig. 11. The English course resource management module 


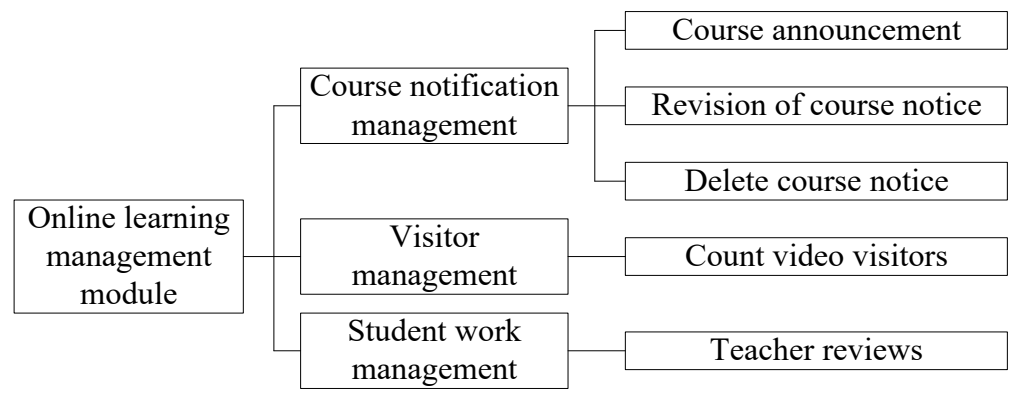

Fig. 12. The online learning management module

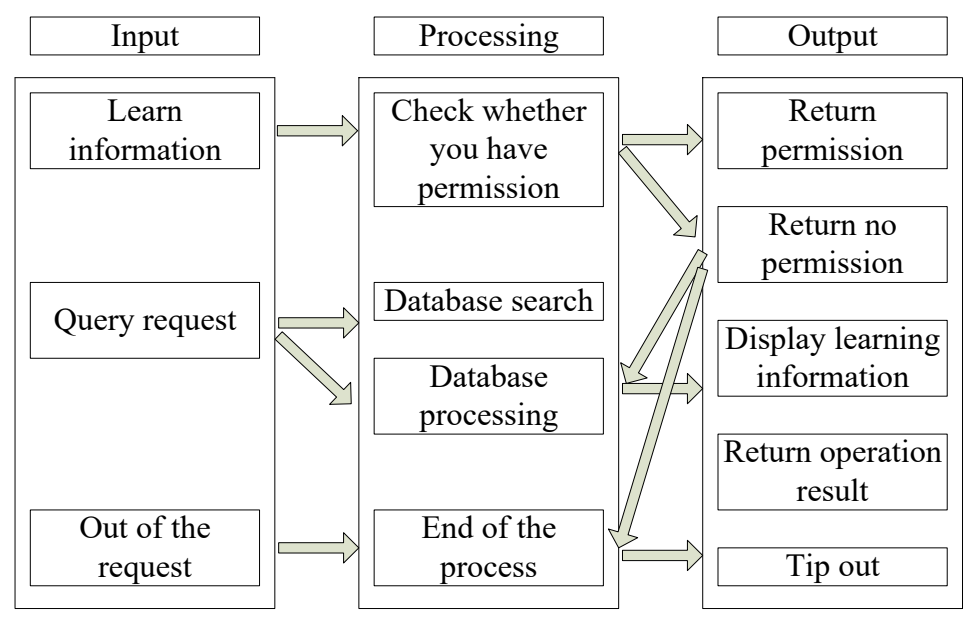

Fig. 13. Input-process-output diagram of online learning management.

\section{Conclusion}

Based on mobile Internet technology, this paper designed functional modules of an IOEL system and implemented the proposed system, the specific conclusions are as follows:

1. Intelligent online learning mainly has four features: personalized self-directed learning, mobile learning environment, diverse learning resources, contextual and interactive learning process.

2. Data mining includes three stages of data preparation, data mining, result expression and interpretation. The data preparation stage contains steps of data integration, data selection and data pre-processing.

3. The proposed IOEL system has two parts: web-end management system, and the mobile-end app. Main functions of the web-end management system include: question bank import, video upload, question bank management, test management, user 
management, score analysis, and test question analysis. Main functions of the mobile-end app include: login $\&$ authorization, question bank exercises, online exams, teaching videos, history records, exam rankings, and personal information, etc.

4. The functions of the English course resource management module include: course video resource management, courseware management, and after-school exercise management. The functions of the online learning module include: course notification management, visitor management, and student homework management.

\section{Acknowledgment}

Research and Practice Project on School-level Teaching Reform of Beijing Jiaotong University Haibin College (Project Code: HBJY19002).

Research and Practice Project on Teaching Reform in Higher Education in Hebei Province (Project Code: 2019GJJG638).

Research on the Blended Teaching Model of College English Based on "Productionoriented Approach".

\section{$7 \quad$ References}

[1] Liu, L., Peng, N. (2021). Evaluation of user concentration in ubiquitous and cognitive artificial intelligence-assisted English online guiding system integrating face and eye movement detection. International Journal of Communication Systems, 34(6): 1-14. https://doi.org/ $10.1002 /$ dac. 4580

[2] Wang, Y. (2019). Functions, values \& inadequacies-an evaluative discussion of Pigai intelligent online English writing correction system in view of second language acquisition. Journal of Physics Conference Series, 1237(4): 042002. https://doi.org/10.1088/17426596/1237/4/042002

[3] Hwang, G.J., Cheng, H., Chu, C., Tseng, J., Hwang, G.H. (2007). Development of a webbased system for diagnosing student learning problems on English tenses. International Journal of Distance Education Technologies, 5(4): 80-98. https://doi.org/10.4018/jdet. $\underline{2007100105}$

[4] Almekhlafy, S. (2020). Online learning of English language courses via blackboard at saudi universities in the era of covid-19: perception and use. PSU Research Review, 5(1): 6-32. https://doi.org/10.1108/PRR-08-2020-0026

[5] Cheng, S.C., Hwang, W.Y., Wu, S.Y., Shadiev, R., Xie, C.H. (2010). A mobile device and online system with contextual familiarity and its effects on English learning on campus. Journal of Educational Technology \& Society, 13(3): 93-109.

[6] Toffoli, S.D. (2012). Beyond learner autonomy: a dynamic systems view of the informal learning of English in virtual online communities. Procedia - Social and Behavioral Sciences, 24(2): 138-151. https://doi.org/10.1016/j.sbspro.2012.02.042

[7] Sockett, G. (2013). Understanding the online informal learning of English as a complex dynamic system: an emic approach. ReCall, 25(1): 48-62. https://doi.org/10.1017 /s095834401200033x

[8] Luke, J.K., Sela, S.T., Yunus, U. (2021). Perspectives of computer science students on online learning quality and learning apps for sustaining communicative competence growth. 
Paper-Design and Implementation of an Intelligent Online English Learning System Based on Mobile...

IOP Conference Series: Earth and Environmental Science, 729(1): 012129 (5pp). https://doi.org/10.1088/1755-1315/729/1/012129

[9] Yang, Y., Gamble, J.H., Hung, Y.W., Lin, T.Y. (2014). An online adaptive learning environment for critical-thinking-infused English literacy instruction. British Journal of Educational Technology, 45(4): 723-747. https://doi.org/10.1111/bjet.12080

[10] Nasir, M., Hasyimi, Mahdi, Amru. (2019). Modeling system test of English as a foreign language as a web-based learning media. IOP Conference Series: Materials Science and Engineering, 536(1): 012130. https://doi.org/10.1088/1757-899x/536/1/012130

[11] Chen, G., Chau, J. (2015). Exploring the relationships between learning styles, online participation, learning achievement and course satisfaction: an empirical study of a blended learning course. British Journal of Educational Technology, 47(2): 371-378. https://doi.org/ $\underline{10.1111 / \text { bjet. } 12243}$

[12] Chen, C.M., Wang, J.Y., Chen, Y.C. (2014). Facilitating English-language reading performance by a digital reading annotation system with self-regulated learning mechanisms. Educational Technology \& Society, 17(1): 102-114.

[13] Dogoriti, E., Pange, J., Anderson, G.S. (2014). The use of social networking and learning management systems in English language teaching in higher education. Campus Wide Information Systems, 31(4): 2-3. https://doi.org/10.1108/cwis-11-2013-0062

[14] Dharminder, D. (2021). Lwedm: learning with error based secure mobile digital rights management system. Transactions on Emerging Telecommunications Technologies, 32(2): e4199. https://doi.org/10.1002/ett.4199

[15] Lin, H.H., Lin, S.J., Yeh, C.H., Wang, Y.S. (2016). Measuring mobile learning readiness: scale development and validation. Internet Research, 26(1): 265-287. https://doi.org/10. $\underline{1108 / \text { intr-10-2014-0241 }}$

[16] Wen, J., Wei, X.C., He, T., Zhang, S.S. (2020). Regression analysis on the influencing factors of the acceptance of online education platform among college students. Ingénierie des Systèmes d'Information, 25(5): 595-600. https://doi.org/10.18280/isi.250506

[17] Ashour, A.F. (2020). Design responsibility and sustainability in education. International Journal of Design \& Nature and Ecodynamics, 15(1): 129-133. https://doi.org/10. $\underline{18280 / \text { ijdne. } 150117}$

[18] Turgut, Z., Ustebay, S., Ali Aydin, M., Gurkas, G.Z., Sertbas, A. (2019). Performance analysis of machine learning and deep learning classification methods for indoor localization in internet of things environment. Transactions on Emerging Telecommunications Technologies, 30(9): e3705. https://doi.org/10.1002/ett.3705

[19] Clough, G. (2010). Geolearners: location-based informal learning with mobile and social technologies. IEEE Transactions on Learning Technologies, 3(1): 33-44. https://doi.org/ $\underline{10.1109 / \text { tlt.2009.39 }}$

[20] Meng, H., Chao, D., Guo, Q., Li, X. (2019). Delay-sensitive task scheduling with deep reinforcement learning in mobile-edge computing systems. Journal of Physics: Conference Series, 1229(1): 012059. https://doi.org/10.1088/1742-6596/1229/1/012059

[21] Chen, X., Li, Z., Tang, C., Xiao, S., Chen, Y. (2019). Person re-identification in the edge computing system: a deep square similarity learning approach. Concurrency and Computation Practice and Experience, (5): e5360. https://doi.org/10.1002/cpe.5360

[22] Saracchini, R., Catalina, C., Bordoni, L. (2015). A mobile augmented reality assistive technology for the elderly. Comunicar, 23(45): 65-74. https://doi.org/10.3916/c45-2015-07

[23] Che, P.C., Lin, H.Y., Jang, H.C., Lien, Y.N., Tsai, T.C. (2011). A study of English mobile learning applications at national Chengchi university. International Journal of Distance Education Technologies, 7(4): 38-60. https://doi.org/10.4018/978-1-60960-539-1.ch018 
Paper-Design and Implementation of an Intelligent Online English Learning System Based on Mobile...

[24] Lucia, A.D., Francese, R., Passero, I., Tortora, G. (2012). A collaborative augmented campus based on location-aware mobile technology. International Journal of Distance Education Technologies, 10(1): 55-73. https://doi.org/10.4018/jdet.2012010104

[25] Liu, T.Y., Tan, T.H. (2009). Outdoor natural science learning with an RFID-supported immersive ubiquitous learning environment. Journal of Educational Technology \& Society, 12(4): 161-175.

[26] Pei, J.Y., Shan, P. (2019). A micro-expression recognition algorithm for students in classroom learning based on convolutional neural network. Traitement du Signal, 36(6): 557563. https://doi.org/10.18280/ts.360611

[27] Al-Zoube, M., El-Seoud, S.A., Wyne, M.F. (2010). Cloud computing based e-learning system. International journal of distance education technologies, 8(2): 58-71. https://doi.org/ 10.4018/jdet.2010040105

[28] Wei, F.H., Chen, G.D. (2010). Collaborative mentor support in a learning context using a ubiquitous discussion forum to facilitate knowledge sharing for lifelong learning. British Journal of Educational Technology, 37(6): 917-936. https://doi.org/10.1111/j.14678535.2006.00674.x

[29] Hu, H.P., Li, J., Lei, X.Y., Qin, P.P., Chen, Q. (2019). Design of health statistics intelligent education system based on internet + . Journal of Physics: Conference Series, 1168(6): 62003. https://doi.org/10.1088/1742-6596/1168/6/062003

[30] Caverly, D.C., Ward, A. (2009). Techtalk: Mobile learning and access. Journal of Developmental Education, 33(1): 38-39.

[31] Fabian, P., Rachedi, A., Guéguen, C. (2021). Selection of relays based on the classification of mobility-type and localized network metrics in the internet of vehicles. Transactions on Emerging Telecommunications Technologies, 32(4): e4246. https://doi.org/10.1002/ $\underline{\text { ett.4246 }}$

[32] Ju, S.L., Lee, K. (2021). The role of informal digital learning of English and 12 motivational self system in foreign language enjoyment. British Journal of Educational Technology, 52(1): 358-373. https://doi.org/10.1111/bjet.12955

\section{Authors}

Ying Liu was born in City of Chengde, Hebei, China on Feb. 1979. She was granted B.A. and M.A. in Hebei Normal University, majoring in English Linguistics and Literature. Since 2001, she has been teaching English language in Foreign Language Teaching Department, Chengde Medical University. Apart from that, she had one year as Chinese language teacher at Portland State University, Oregon, U.S.A, and another one year as visiting scholar at Peking University. Sha has authored more than ten papers in English teaching, and host four research projects (email: liuying@cdmc.edu.cn).

Hong Yan was born on August 5, 1980, in Handan City, Hebei Province, China. She received her B.A. degree in English from Hebei Normal University in 2005 and a master degree in History of Foreign Education from Shandong Normal University in 2008. She started her teaching career in 2008 in School of Foreign Languages, Beijing Jiaotong University Haibin College. Since 2009, she has authored 8 papers in English teaching, compiled 2 teaching materials on English listening and reading, participated in a provincial and a municipal research projects.

Article submitted 2021-10-05. Resubmitted 2021-10-29. Final acceptance 2021-10-30. Final version published as submitted by the authors. 